\title{
Schottky Junction Methane Sensors Using Electrochemically Grown Nanocrystalline-Nanoporous ZnO Thin Films
}

\author{
P. K. Basu, ${ }^{1}$ N. Saha, ${ }^{1}$ S. K. Jana, ${ }^{1}$ H. Saha, ${ }^{1}$ A. Lloyd Spetz, ${ }^{2}$ and S. Basu ${ }^{1}$ \\ ${ }^{1}$ Department of Electronics \& Telecommunication Engineering, IC. Design \& Fabrication Centre, Jadavpur University, \\ Kolkata 700032, India \\ ${ }^{2}$ Department of Physics, Chemistry and Biology, Linkoping University, SE-581 83 Linköping, Sweden
}

Correspondence should be addressed to S. Basu, sukumar_basu@yahoo.co.uk

Received 29 December 2008; Accepted 1 July 2009

Recommended by Giorgio Sberveglieri

Nanocrystalline-nanoporous $\mathrm{ZnO}$ thin films were prepared by an electrochemical anodization method, and the films were tested as methane sensors. It was found that Pd-Ag catalytic contacts showed better sensing performance compared to other noble metal contacts like Pt and $\mathrm{Rh}$. The methane sensing temperature could be reduced to as low as $100^{\circ} \mathrm{C}$ by sensitizing nanocrystalline $\mathrm{ZnO}$ thin films with Pd, deposited by chemical method. The sensing mechanism has been discussed briefly.

Copyright (c) 2009 P. K. Basu et al. This is an open access article distributed under the Creative Commons Attribution License, which permits unrestricted use, distribution, and reproduction in any medium, provided the original work is properly cited.

\section{Introduction}

It is well known that gas sensing performance of sensors can be improved by incorporating noble catalyst metal into the nanocrystalline metal oxide-based matrix. A number of reports [1-3] have been published on nanocrystalline $\mathrm{ZnO}$ thin films to improve the methane sensing performance. The development of a low-temperature methane detector using nanocrystalline $\mathrm{ZnO}$-based chemical gas sensors with noble metal catalytic contacts is an important proposition. The challenge is to attain lower detection limit, short response time, and long-term stability of the gas sensors. Nanocrystalline $\mathrm{ZnO}$ thin films demonstrate remarkable gas-sensing properties when the crystallite size becomes comparable to Debye length. Nanocrystalline and porous materials with controlled composition are of increasing interest in methane sensing because of their large surface to volume ratio that enhances the adsorption kinetics and the reaction between methane and adsorbed oxygen.

Recently it was [1-6] reported that methane-sensing temperature varies between $100^{\circ} \mathrm{C}$ and $250^{\circ} \mathrm{C}$ depending upon whether the $\mathrm{ZnO}$ thin film is grown electrochemically or by sol-gel method and upon the nature of the catalytic metals. But these relatively high temperatures for detection of methane are still not suitable for applications in the coalmines. In this work, nanocrystalline $\mathrm{ZnO}$ thin films were prepared by electrochemical anodization of high-purity $\mathrm{Zn}$ (99.99\%). While using Pt catalytic metal electrode methane sensing could be achieved at $240^{\circ} \mathrm{C} \mathrm{Pd}-\mathrm{Ag}(26 \%)$, and $\mathrm{Rh}$ electrodes could bring down the temperature to $210^{\circ} \mathrm{C}$. But the temperature could be brought down to $100^{\circ} \mathrm{C}$ by incorporating $\mathrm{Pd}$ modification of the nanocrystalline $\mathrm{ZnO}$ thin film and by using Pd-Ag catalytic metal Schottky contact. In this communication, a comparative study between $\mathrm{ZnO}$ Schottky devices with different catalytic metal contacts and the effect of adding $\mathrm{Pd}$ to the nanoporous $\mathrm{ZnO}$ are presented.

\section{Experimental}

The noble metal/ZnO Schottky structure using nanocrystalline $\mathrm{ZnO}$ thin film, prepared by electrochemical anodization of $\mathrm{Zn}$, was studied for gas sensing. A properly cleaned high-purity $\mathrm{Zn}$ foil of thickness $0.5 \mathrm{~mm}$ was taken as anode and platinum foil as cathode with $18 \mathrm{~mm}$ separation between the two electrodes and $0.3 \mathrm{M}$ oxalic acid as electrolyte. A calomel electrode was taken as the reference. A $10 \mathrm{~V}$ potentiostatic power supply (Princeton Applied Research, Scanning Potentiostat-362, USA) was used during anodization. Sensitization of the grown $\mathrm{ZnO}$ films was performed by dipping into $0.01 \mathrm{M}$ weak acidic aqueous solution of $\mathrm{PdCl}_{2}$ for 2 seconds followed by baking at $110^{\circ} \mathrm{C}$ for 10 


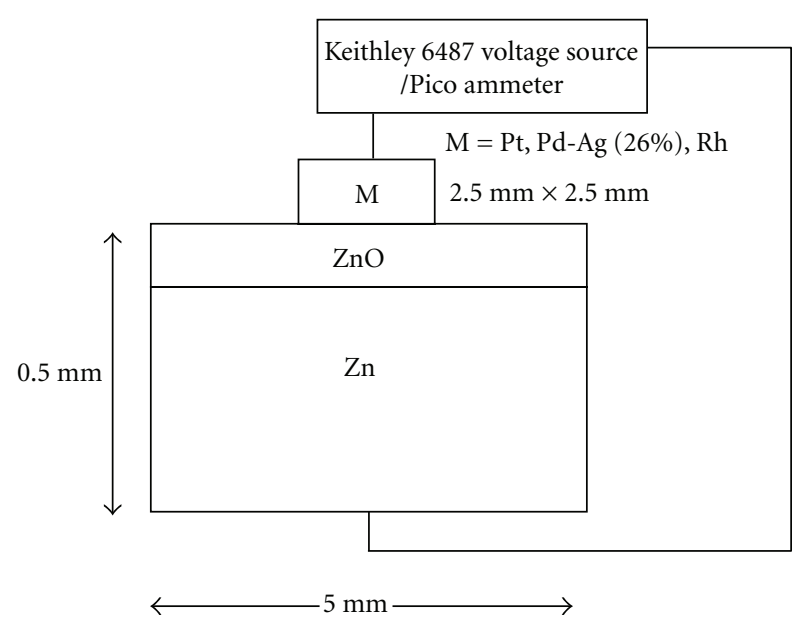

Figure 1: Schemetic of the ZnO based Schottky sensor.

TABLE 1: The crystal size, pore size, and thickness of the anodized $\mathrm{ZnO}$ thin films.

\begin{tabular}{lc}
\hline Parameters & Anodized $\mathrm{ZnO}$ \\
\hline Crystal size $(\mathrm{nm})$ & 2.40 \\
Pore size $(\mathrm{nm})$ & $19-35$ \\
Thickness $(\mu \mathrm{m})$ & 8.20 \\
\hline
\end{tabular}

minutes and annealing at $300^{\circ} \mathrm{C}$ in air for 30 minutes. $\mathrm{Pt}$, Pd-Ag (26\%) and Rh catalytic metals $(2.5 \mathrm{~mm} \times 2.5 \mathrm{~mm})$ of thickness $0.2 \mu \mathrm{m}$ were deposited on $\mathrm{ZnO}$ films by ebeam evaporation using Al metal mask for Schottky contacts. The $\mathrm{Zn}$ substrate beneath the $\mathrm{ZnO}$ film was used as ohmic contact. Electrical connections were performed by using fine copper wire and silver paste. The schematic of the Schottky sensor structure is shown in Figure 1. In order to study the gas sensing properties high-purity methane, nitrogen, and synthetic air were used. For accurate control of the gas flow rate throughout the experiments, mass flow controller and mass flow meters (Digiflow, USA) were used. The currentvoltage characteristics of the sensors were studied by a Keithley model 6487 Pico ammeters-voltage source.

\section{Results and Discussions}

The XRD and the FESEM (Field Effect Scanning Electron Microscopy) picture of the anodized $\mathrm{ZnO}$ thin films are shown in Figure 2. The average crystal size, the pore diameter, and the thickness are summarized in Table 1.

The V-I characteristics of the Schottky sensors were recorded at all the temperatures of measurements, and the magnitude of the response $(S)$ was calculated from these data. The response $(S)$ is defined as the ratio of the change of current in presence of methane in $\mathrm{N}_{2}$ or air to the current in $\mathrm{N}_{2}$ or air at constant voltage, both in the forward bias mode

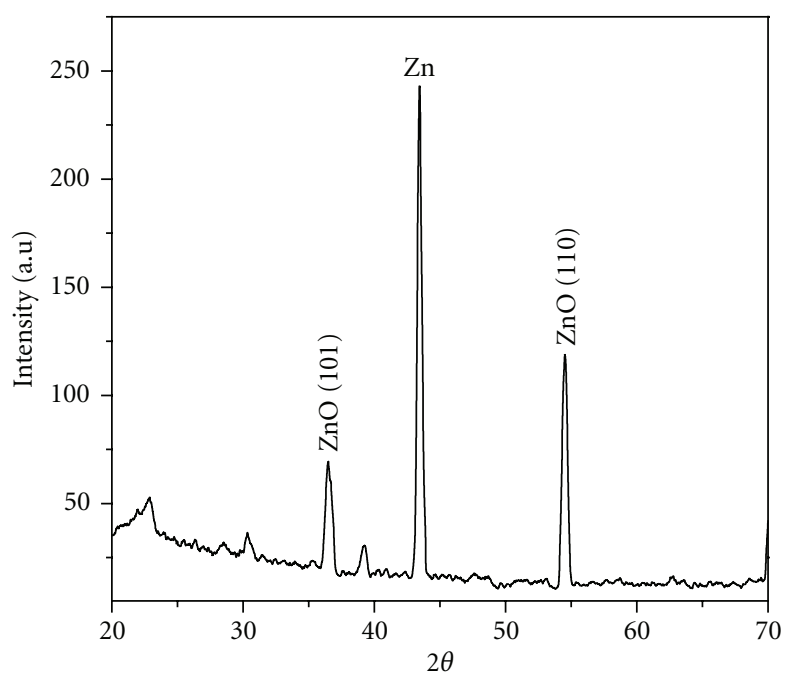

(a)

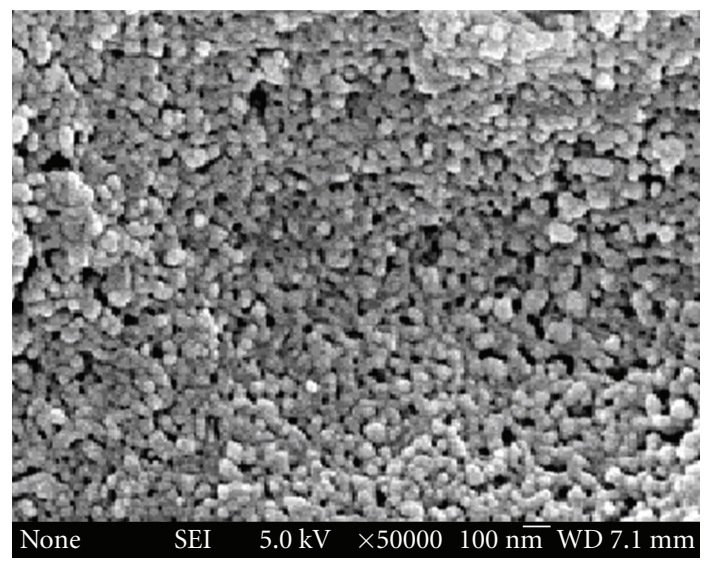

(b)

Figure 2: (a) XRD and (b) FESEM of $\mathrm{ZnO}$ thin films obtained by anodic oxidation of $\mathrm{Zn}$ in $0.3 \mathrm{M}$ oxalic acid.

and expressed as

$$
S=\left(\frac{I_{g}-I_{a}}{I_{a}}\right)_{V},
$$

where $I_{g}$ is the current in presence of gas and $I_{a}$ is the current in $\mathrm{N}_{2}$ or air.

Figure 3(a) shows response versus temperature curves of the Schottky sensors with the unsensitized $\mathrm{ZnO}$ films using $1 \% \mathrm{CH}_{4}$ in pure $\mathrm{N}_{2}$. For Pt contact the maximum response was obtained at $240^{\circ} \mathrm{C}$ while for $\mathrm{Pd}-\mathrm{Ag}$ and $\mathrm{Rh}$ contacts the maximum response was obtained at $210^{\circ} \mathrm{C}$. For all three types of contacts the maximum response was obtained at $0.4 \mathrm{~V}$ bias, as shown in Figure 3(b). This may be significant for low power consumption of the sensor devices. Figure 4 shows the response versus temperature curves with $1 \% \mathrm{CH}_{4}$ in pure $\mathrm{N}_{2}$ and in synthetic air, respectively. It is observed that the response of the sensors is higher in nitrogen compared to that in synthetic air.

In case of the Schottky gas sensors, catalytic noble metals were taken as electrode contacts. At an elevated temperature, 


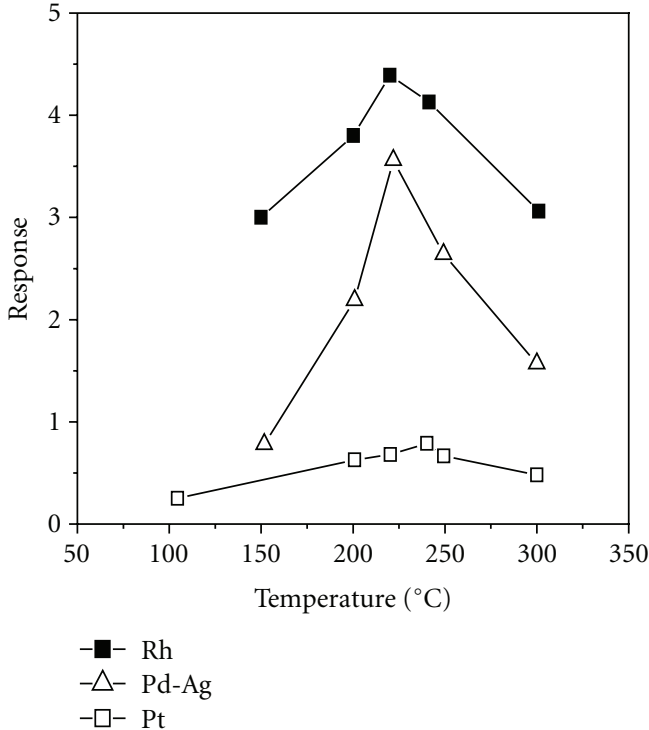

(a)

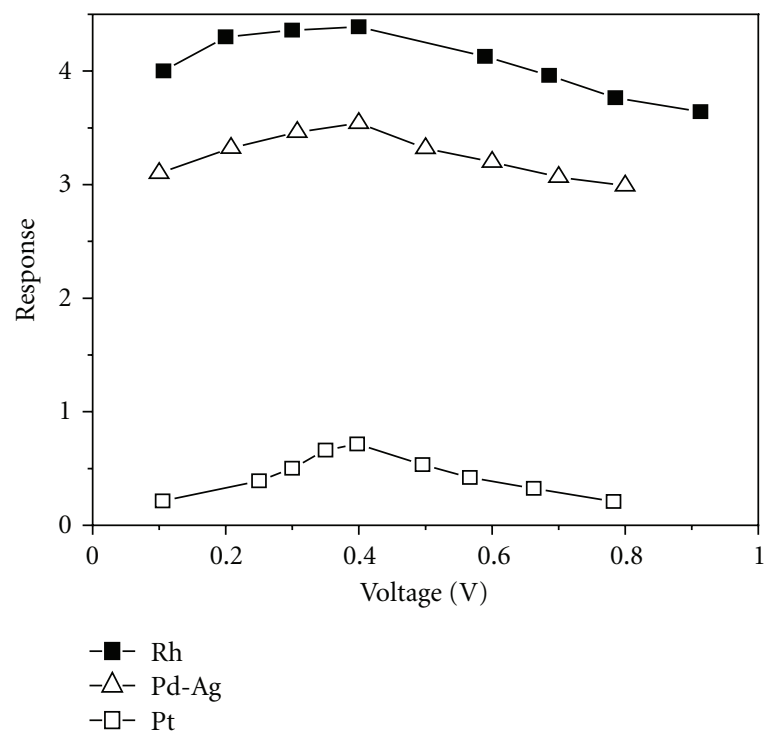

(b)

FIgURE 3: (a) Response versus temperature curves and (b) response versus voltage curves of the Schottky sensors using different catalytic contacts on $\mathrm{ZnO}$ thin films. It is observed that $\mathrm{Rh}$ gives maximum response. For Pt contact the maximum response was obtained at $240^{\circ} \mathrm{C}$ while for Pd-Ag and $\mathrm{Rh}$ contacts the maximum response was obtained at $210^{\circ} \mathrm{C}$. For all three types of contacts the maximum response was obtained at $0.4 \mathrm{~V}$ bias.

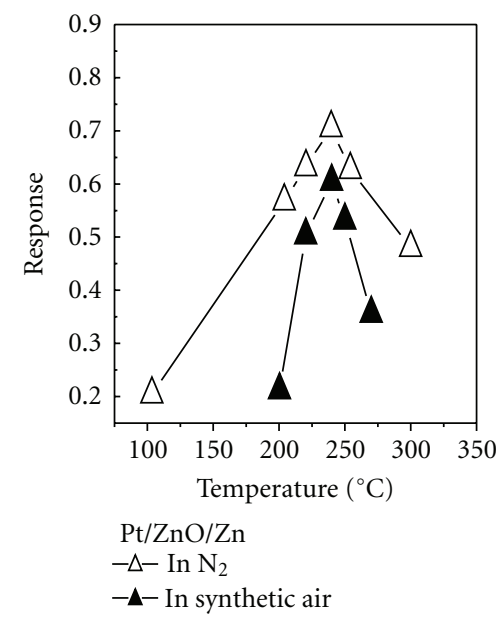

(a)

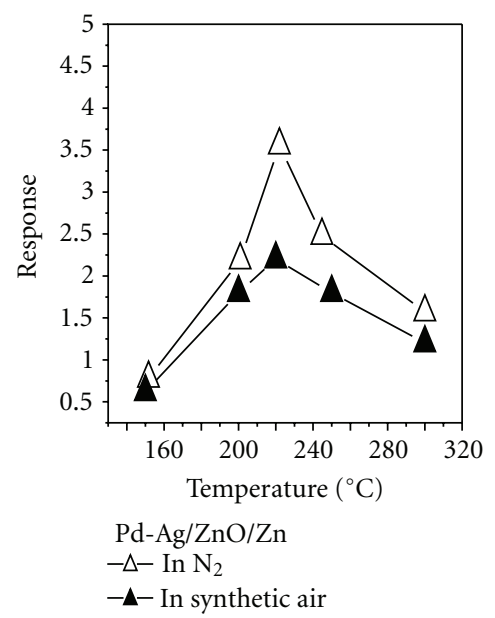

(b)

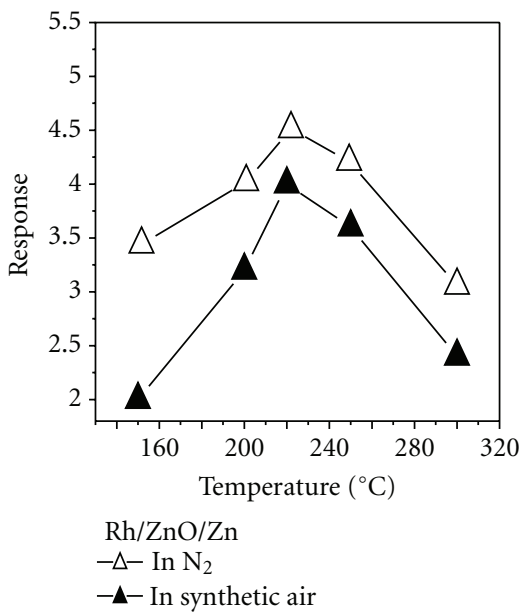

(c)

Figure 4: Response versus temperature curves of the (a) Pt/ZnO/Zn, (b) Pd-Ag (26\%)/ZnO/Zn, and (c) Rh/ZnO/Zn Schottky sensors in presence of $1 \%$ methane in pure nitrogen and in synthetic air, respectively. The response of the sensors is higher in nitrogen than in synthetic air.

oxygen molecules are weakly bonded to the catalytic metal ( $\mathrm{Pt}, \mathrm{Pd}-\mathrm{Ag}$, and $\mathrm{Rh}$ ) and are dissociated to oxygen atoms that are weakly adsorbed on the metal surface. The metal-oxygen complex subsequently dissociates

$$
\begin{aligned}
& 2 \mathrm{M}+\mathrm{O}_{2} \longrightarrow 2 \mathrm{M}: \mathrm{O}[\mathrm{M}=\mathrm{Pd}, \mathrm{Pt}, \mathrm{Rh}], \\
& 2 \mathrm{M}: \mathrm{O} \longrightarrow 2 \mathrm{M}+2 \mathrm{O} .
\end{aligned}
$$

The oxygen atoms then undergo a spillover process and finally form negatively charged surface ions by gaining electrons from the surface of $\mathrm{ZnO}$, thereby yielding a high electrostatic potential in the junction [7-9]. The space charge region, being depleted of electrons, is more resistive than the bulk. The methane response mechanism with a noble metal/metal oxide Schottky junction is not so well understood and spectroscopic studies are needed in order to reveal the reaction pathways that may be different for different temperatures and even vary with the gas concentration. Here we present three possible mechanisms of gas sensors. The first is dissociative adsorption of $\mathrm{CH}_{4}$ to produce $\mathrm{H}$ and 


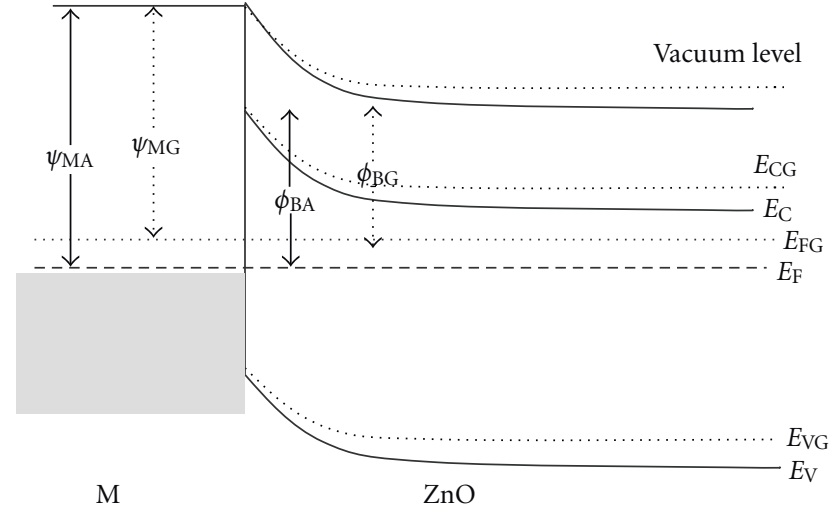

Figure 5: Band diagram of the Schottky Junction explaining the sensing mechanism. The barrier height reduces upon exposure to the reducing gas. $\psi_{\mathrm{MA}}, \psi_{\mathrm{MG}}$ are the work function of $\mathrm{M}$ in air and in gas, respectively. $\Phi_{\mathrm{BA}}, \Phi_{\mathrm{BG}}$ are the barrier height of the junction in air and in gas, respectively. $E_{\mathrm{C}}, E_{\mathrm{CG}}$ are the conduction band in air and in gas, respectively. $E_{\mathrm{V}}, E_{\mathrm{VG}}$ are the valence band in air and in gas, respectively. $E_{\mathrm{F}}, E_{\mathrm{FG}}$ are the Fermi level in air and in gas, respectively, $\mathrm{M}=\mathrm{Pt}, \mathrm{Pd}$, or $\mathrm{Rh}$.

$\mathrm{CHx}(\mathrm{X}=3)$ on the noble metal surface and reaction with adsorbed atomic oxygen to produce water. Furthermore, the $\mathrm{H}$ or $\mathrm{CHx}$ spills over to the metal oxide and reacts with chemisorbed ionic oxygen to produce water and free electrons that increase the current through the junction. If the device is operated at a temperature of $\geq 100^{\circ} \mathrm{C}$, which is normally the case for methane sensing, the water formed desorbs rapidly from the surface [10-12] (see reactions (3)):

$$
\begin{aligned}
& \mathrm{CH}_{4} \longrightarrow \mathrm{CH}_{3(\mathrm{ads})}+\mathrm{H}_{(\mathrm{ads})}, \\
& \mathrm{CH}_{3}+\mathrm{H}+4 \mathrm{O}^{-} \longrightarrow \mathrm{CO}_{2}+2 \mathrm{H}_{2} \mathrm{O}+4 \mathrm{e}^{-}, \\
& \mathrm{CH}_{4}+4 \mathrm{O}^{-} \longrightarrow \mathrm{CO}_{2}+2 \mathrm{H}_{2} \mathrm{O}+4 \mathrm{e}^{-} \text {(Complete reaction). }
\end{aligned}
$$

A second possibility is that due to high solubility and rapid diffusivity of hydrogen through catalytic metal, it reaches the catalytic metal/metal oxide interfaces and produces an interfacial dipole layer. The electrically polarized potential at the interface also lowers the work function of the noble metal and thus reduces the barrier height. Such sensing mechanism is summarized in Figure 5, where the reduction of the barrier height upon exposure to the reducing gas is shown. The adsorbed hydrogen atoms may, as a third possibility, passivate the interface states at the noble metal/metal oxide interface, preventing them from pinning the Fermi level. The passivated interface thus might cause a decrease in the barrier height. Due to this lowering of barrier height, the current through the junction increases $[6,13]$, yielding thereby a high response.

Palladium (Pd), Silver (Ag), Platinum (Pt), and Rhodium $(\mathrm{Rh})$ are the most common metal catalysts that are used to improve the gas-sensing properties. Here $\mathrm{Pt}, \mathrm{Pd}-\mathrm{Ag}$, and $\mathrm{Rh}$ catalysts were used for gas sensing applications. A Pd$\mathrm{Ag}(26 \%)$ alloy metal contact was used instead of pure Pd. The reason is that the phase transition from $\alpha$ phase of pure

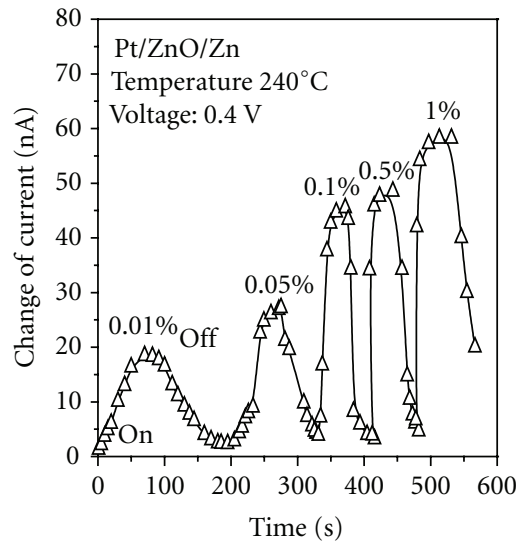

(a)

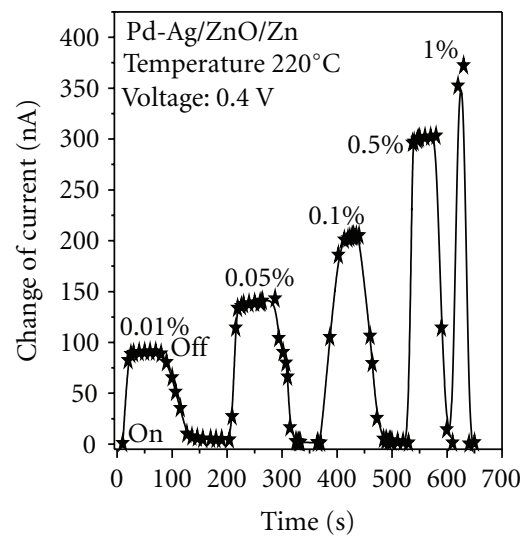

(b)

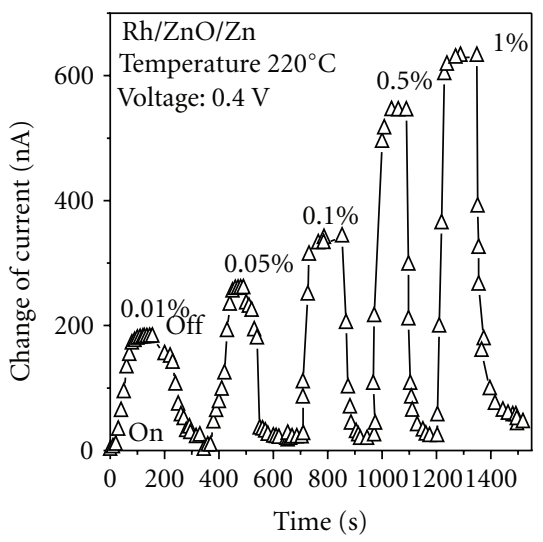

(c)

Figure 6: Transient response curves of (a) Pt/ZnO/Zn, (b) Pd-Ag (26\%)/ZnO/Zn, (c) $\mathrm{Rh} / \mathrm{ZnO} / \mathrm{Zn}$ Schottky sensors at $0.4 \mathrm{~V}$ bias.

palladium to $\beta$ phase hydride occurs at low $\mathrm{H}_{2}$ concentration at $300 \mathrm{~K}$ and it is an irreversible process [14]. This will damage the sensor due to peeling-off of Pd. Moreover, the response time of more than 10 minutes for pure $\mathrm{Pd}$ contact sensors, as reported in the literature [15], is too long to allow real-time monitoring of flowing gas streams. To overcome these problems Pd was alloyed with $26 \% \mathrm{Ag}$ for $\mathrm{CH}_{4}$ sensing. Pd-Ag thin film is attractive for use [14] 
TABLE 2: Response, response time, and recovery time of different noble metal contacts on ZnO thin film (calculated from Figure 6).

\begin{tabular}{lccccccccc}
\hline \% of $\mathrm{CH}_{4}$ & \multicolumn{3}{c}{ Response } & \multicolumn{3}{c}{ Response time $(\mathrm{s})$} & \multicolumn{3}{c}{ Recovery time $(\mathrm{s})$} \\
& $\mathrm{Pt}$ & $\mathrm{Pd}-\mathrm{Ag}$ & $\mathrm{Rh}$ & $\mathrm{Pt}$ & $\mathrm{Pd}-\mathrm{Ag}$ & $\mathrm{Rh}$ & $\mathrm{Pt}$ & $\mathrm{Pd}-\mathrm{Ag}$ & \multicolumn{2}{c}{ Rh } \\
\hline 0.01 & 0.18 & 0.99 & 1.22 & 52.2 & 22.3 & 130.2 & 58.3 & 148.3 \\
0.05 & 0.29 & 1.38 & 1.82 & 40.2 & 19.7 & 52.2 & 42.3 & 46.2 & 120 \\
0.1 & 0.62 & 2.21 & 2.48 & 27.9 & 16.4 & 42.8 & 30.1 & 38.1 & 89.2 \\
0.5 & 0.68 & 3.11 & 3.87 & 20.3 & 12.1 & 38.2 & 26.2 & 20.2 \\
1 & 0.71 & 3.81 & 4.39 & 18.8 & 8.8 & 30.2 & 22.8 & 16 & 78.2 \\
\hline
\end{tabular}

TABLE 3: Response, response time, and recovery time of $\mathrm{Pd}-\mathrm{Ag} / \mathrm{ZnO}$ Schottky sensor with different concentrations of $\mathrm{CH}_{4}$ in nitrogen using unmodified and Pd modified $\mathrm{ZnO}$ thin films at the corresponding optimum temperatures and voltages (calculated from Figures 6(b) and $9(\mathrm{a})$.

\begin{tabular}{|c|c|c|c|c|c|c|}
\hline \multirow{2}{*}{$\%$ of $\mathrm{CH}_{4}$} & \multicolumn{2}{|c|}{ Response } & \multicolumn{2}{|c|}{ Response time (s) } & \multicolumn{2}{|c|}{ Recovery time (s) } \\
\hline & $\mathrm{ZnO}$ & Pd: $\mathrm{ZnO}$ & $\mathrm{ZnO}$ & Pd: $\mathrm{ZnO}$ & $\mathrm{ZnO}$ & Pd: $\mathrm{ZnO}$ \\
\hline 0.01 & 0.99 & 18.2 & 22.3 & 10.2 & 48.3 & 18.7 \\
\hline 0.05 & 1.38 & 22.3 & 19.7 & 6.7 & 46.2 & 17.2 \\
\hline 0.1 & 2.21 & 23.2 & 16.4 & 6.03 & 38.1 & 16.8 \\
\hline 0.5 & 3.11 & 25.2 & 12.1 & 4.02 & 20.2 & 16.1 \\
\hline 1 & 3.81 & 32.2 & 8.8 & 2.69 & 16 & 16.0 \\
\hline
\end{tabular}

TABle 4: Response, response time, and recovery time of $\mathrm{Pd}$ modified $\mathrm{Pd}-\mathrm{Ag} / \mathrm{ZnO}$ Schottky sensor with different concentrations of $\mathrm{CH}_{4}$ in nitrogen and in synthetic air as the carrier gas (calculated from Figure 9).

\begin{tabular}{|c|c|c|c|c|c|c|}
\hline \multirow{2}{*}{$\%$ of $\mathrm{CH}_{4}$} & \multicolumn{2}{|c|}{ Response } & \multicolumn{2}{|c|}{ Response time (s) } & \multicolumn{2}{|c|}{ Recovery time (s) } \\
\hline & $\mathrm{N}_{2}$ as carrier gas & $\begin{array}{l}\text { Synthetic air as } \\
\text { carrier gas }\end{array}$ & $\mathrm{N}_{2}$ as carrier gas & $\begin{array}{l}\text { Synthetic air as } \\
\text { carrier gas }\end{array}$ & $\mathrm{N}_{2}$ as carrier gas & $\begin{array}{l}\text { Synthetic air as } \\
\text { carrier gas }\end{array}$ \\
\hline 0.01 & 18.2 & 6.8 & 10.2 & 13.8 & 18.7 & 20.0 \\
\hline 0.05 & 22.3 & 11.0 & 6.7 & 9.9 & 17.2 & 19.7 \\
\hline 0.1 & 23.2 & 17.0 & 6.03 & 8.7 & 16.8 & 17.7 \\
\hline 0.5 & 25.2 & 17.8 & 4.02 & 7.2 & 16.1 & 17.0 \\
\hline 1 & 32.2 & 24.8 & 2.69 & 4.6 & 16.0 & 15.9 \\
\hline
\end{tabular}

because of the low rate of hydride formation, not much hindrance against hydrogen diffusivity, greater solubility of hydrogen, higher energy barrier due to $\mathrm{OH}$ formation and superior mechanical properties as compared to pure $\mathrm{Pd}$. The alloy has quite high rate of hydrogen adsorption in the temperature range $30^{\circ} \mathrm{C}-100^{\circ} \mathrm{C}$ that is important for fast responding gas sensors.

It can be observed that $\mathrm{Rh}$ gives higher response than $\mathrm{Pd}-\mathrm{Ag}$ and $\mathrm{Pt}(\mathrm{Rh}>\mathrm{Pd}-\mathrm{Ag}>\mathrm{Pt})$ because the catalytic effect of dissociation of methane is higher than $\mathrm{Pd}$ and $\mathrm{Pt}$ [16]. Also the $\mathrm{OH}$ formation rate influences the size of the response as discussed below. In literature, it can also be found that the catalytic activity of $\mathrm{Pd}$ and $\mathrm{Pt}$ for methane dissociation is more or less the same [17]. But Figures 3 and 4 show a higher response of $\mathrm{Pd}-\mathrm{Ag}$ alloy than $\mathrm{Pt}$ that implies that the catalytic activity of $\mathrm{Pd}-\mathrm{Ag}$ is higher than that of pure Pd. In case of synthetic air that is shown in Figure 4 it can be noticed that the response is somewhat reduced. Since oxygen is already chemisorbed to a large extent on the noble metal surface the adsorption sites for methane is likely to be reduced. So dissociated hydrogen reacts with chemisorbed oxygen to produce $\mathrm{H}_{2} \mathrm{O}$ molecules instead of diffusing into the noble metal/ZnO junction, thereby yielding a weaker response. Since oxygen adsorption is most favorable on $\mathrm{Pt}$ it gives the most reduced performance in presence of synthetic air as compared to the other two metals, as shown in Figure 4. Similarly the $\mathrm{OH}$ formation energy of Rh is higher than Pd-Ag and Pt [18-21]. Thus this is another reason why the $\mathrm{Rh}$ catalytic metal contact gives higher response than Pd-Ag and Pt. The transient response of the sensors recorded in presence of different methane concentrations $(0.01 \%, 0.05 \%, 0.1 \%, 0.5 \%$, and $1 \%)$ and at $0.4 \mathrm{~V}$ bias is shown in Figure 6. From the transient response cycles the response and recovery time were calculated and are summarized in Table 2. The response time is defined here as the time to reach $67 \%$ of the saturation value of the current. After the gas pulse is cut off the time required to reduce the current to $67 \%$ is defined as the recovery time. It can be observed from Table 2 that the Pd-Ag contact shows shorter response time than $\mathrm{Pt}$ and $\mathrm{Rh}$ contacts, which may be due to the higher solubility and diffusivity of $\mathrm{H}$ in $\mathrm{Pd}$ $\mathrm{Ag}$ compared to $\mathrm{Rh}$ and $\mathrm{Pt}$ and therefore $\mathrm{H}$ takes shorter time to reach the $\mathrm{Pd}-\mathrm{Ag} / \mathrm{ZnO}$ junction compared to that for $\mathrm{Pt} / \mathrm{ZnO}$ and $\mathrm{Rh} / \mathrm{ZnO}$ junctions, but it may also be because 


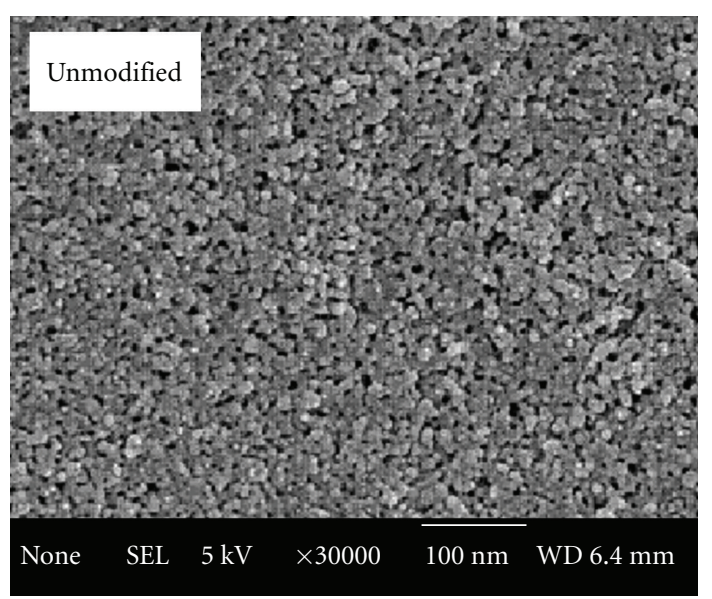

(a)

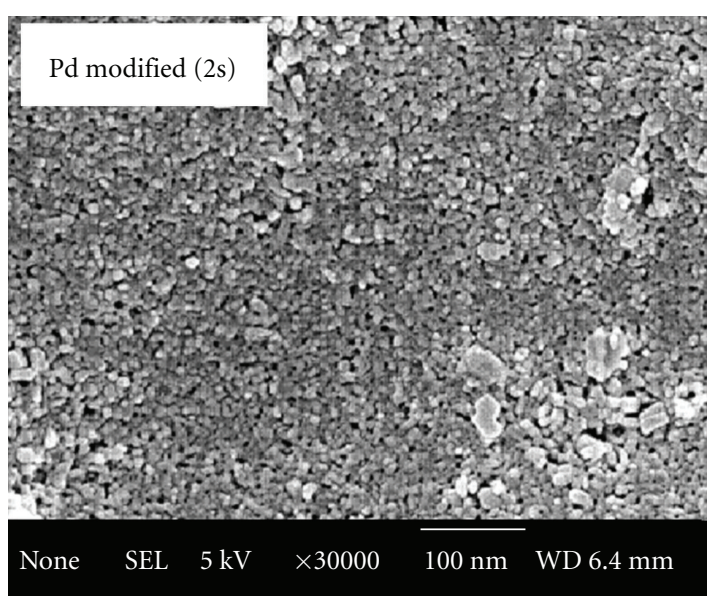

(b)

FIgURE 7: FESEM of (a) unmodified and (b) modified $\mathrm{ZnO}$ thin films. It is observed that there is little or no difference in the surface morphology after treatment with $\mathrm{PdCl}_{2}$ solution [6].

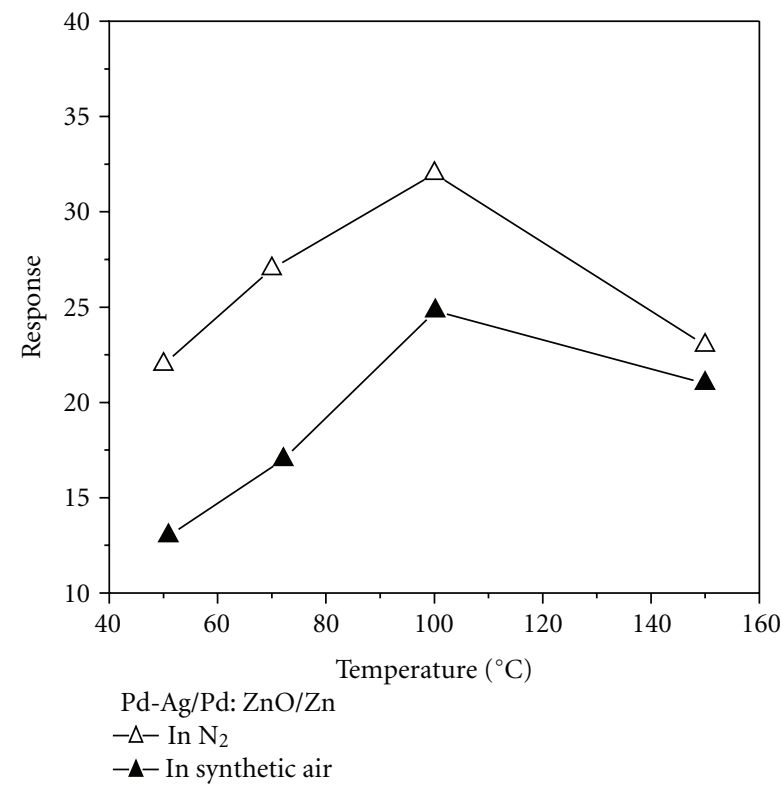

(a)

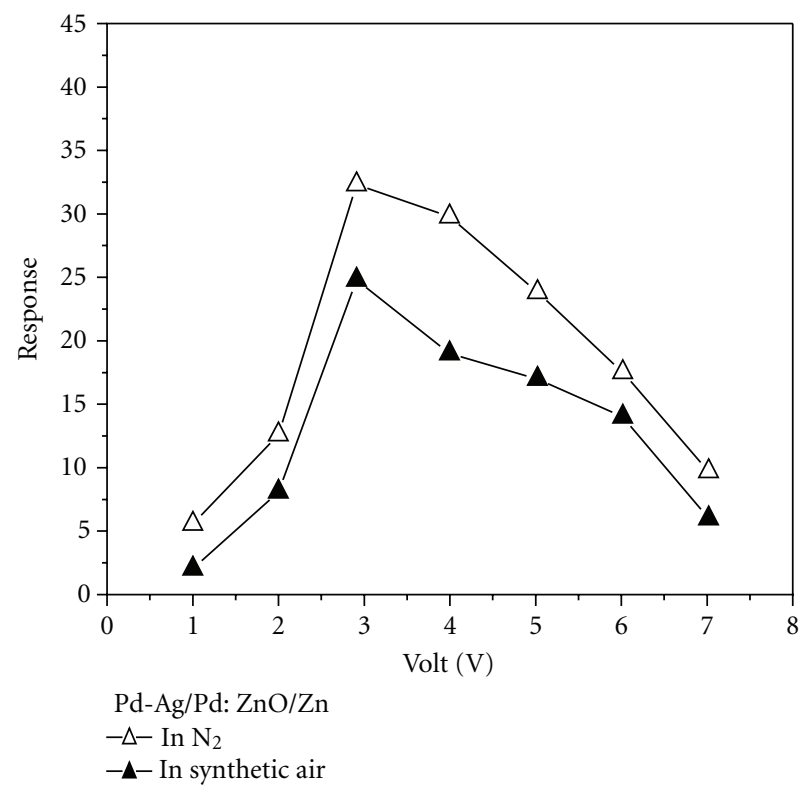

(b)

FIGURE 8: (a) Response versus temperature curves and (b) response versus voltage curves of the Pd modified Schottky sensor. It is observed that the response of the sensor is higher in nitrogen than in synthetic air and the maximum response is obtained at $100^{\circ} \mathrm{C}$ and at $3 \mathrm{~V}$.

of more favorable chemistry on the Pd-Ag surface. This is because the catalytic metal/ZnO is most likely highly porous due to a rather thin catalytic metal $(200 \mathrm{~nm})$ and a highly porous $\mathrm{ZnO}$, which makes diffusion through the metal a noncritical parameter. It should also be noted in Table 2 that the recovery times for Pd-Ag and Pt are about the same. This is most likely because of the back reaction between hydrogen and oxygen for water formation, as well as carbon dioxide formation, on the catalytic metal surface both in the case of nitrogen and synthetic air. It is almost impossible to attain oxygen leakage free systems for measurements at atmospheric pressure in the laboratory. It can be inferred that Pd-Ag alloy is the most suitable catalytic metal amongst the three for methane sensing using the $\mathrm{Pd}-\mathrm{Ag} / \mathrm{ZnO}$ Schottky junction.

There are very few reports on metal oxide based methane gas sensors with high response and fast response and recovery [6]. The reported sensor structures $[1-5]$ on oxide based semiconductors operating in the resistive mode and at high temperatures showed longer response and recovery time. This is not suitable for low temperature applications, particularly in the mining environment. It may also incur higher power consumption and short battery lifetime.

To improve the sensing performance, the surface of $\mathrm{ZnO}$ thin films was chemically modified with Pd. From FESEM the surface morphology and the pore size were revealed for 


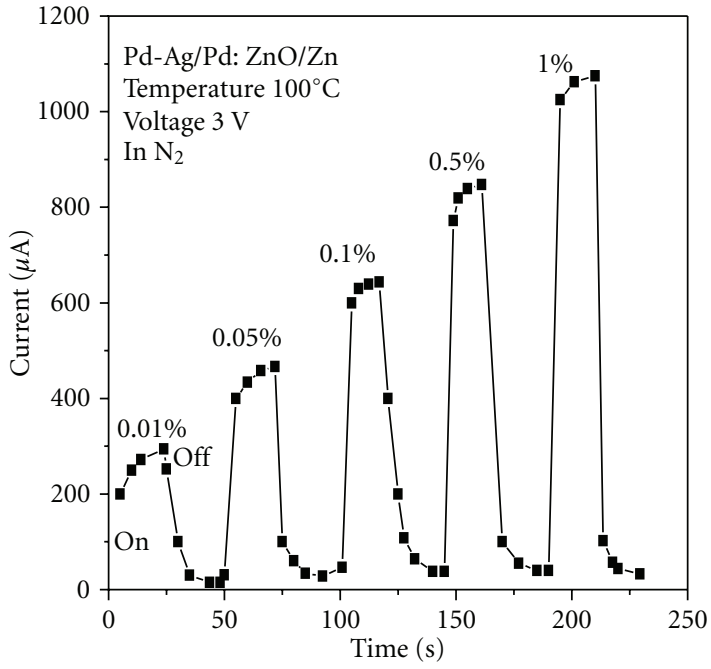

(a)

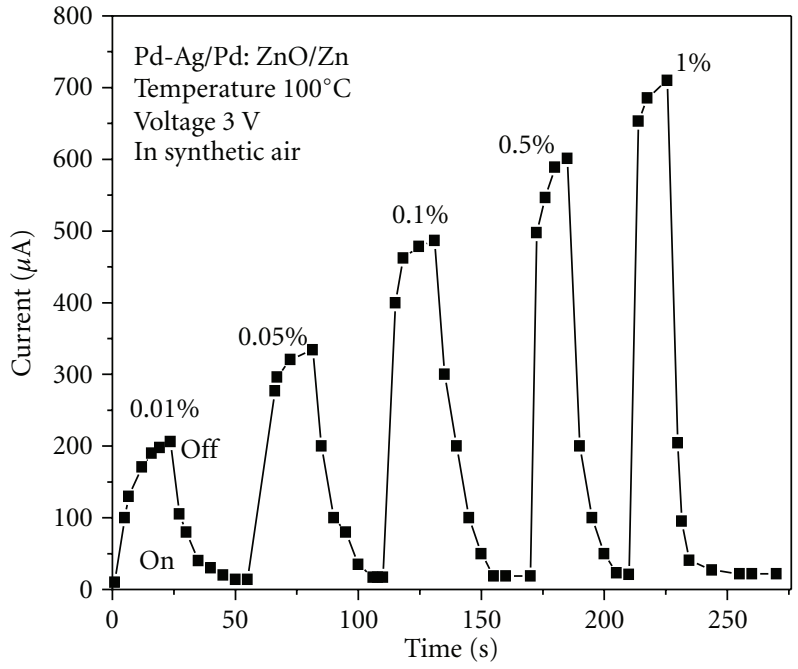

(b)

Figure 9: Transient response curves of the Pd modified Schottky sensor in 1\% methane using (a) nitrogen and (b) synthetic air as the carrier gases at $100^{\circ} \mathrm{C}$ and at $3 \mathrm{~V}$ bias [6].

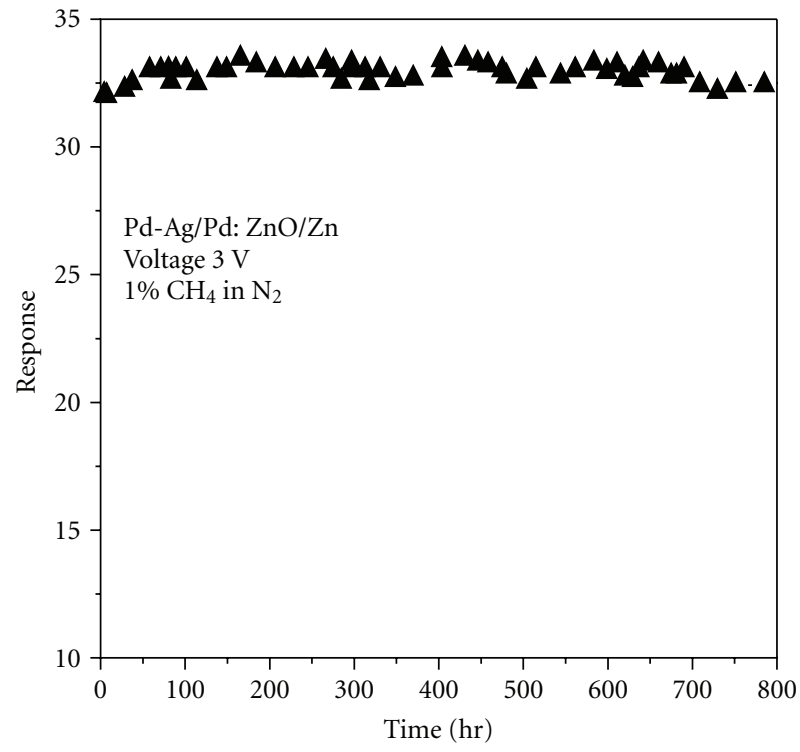

(a)

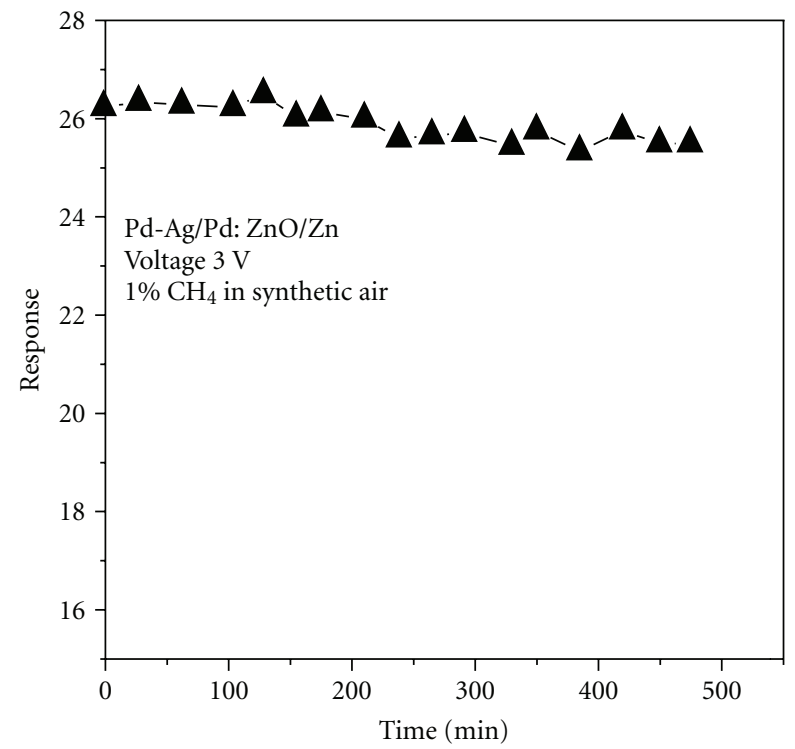

(b)

FIGURE 10: Stability study of the surface modified Schottky sensor structures using (a) nitrogen and (b) synthetic air as the carrier gases. It is observed that the sensor shows more or less stable performance in both the cases. However, the stability in synthetic air initially shows a little deterioration and then stabilizes.

both unmodified and modified $\mathrm{ZnO}$ surfaces (Figure 7). It was observed that there is little or no difference in the surface morphology after treatment with $\mathrm{PdCl}_{2}$ solution [6]. The presence of Pd was confirmed by XPS studies. Table 3 shows the improvement of methane sensing parameters after $\mathrm{Pd}$ surface modification of $\mathrm{ZnO}$ thin film.

The variations of the response with operating temperature and with biasing voltage using $1 \%$ methane in nitrogen and in synthetic air are shown in Figure 8. It is observed from the figure that maximum response was obtained at $100^{\circ} \mathrm{C}$ and at $3 \mathrm{~V}$. It is further observed that the response is higher in pure nitrogen than in synthetic air.

For the nanocrystalline structure the adsorption energy $[22,23]$ is considerably lower, and the presence of dispersed $\mathrm{Pd}$ nanoparticles over $\mathrm{ZnO}$ surface further reduces it. As a result the sensors respond at considerably lower temperature. It is worth mentioning here that imperfect structural orientation of the polycrystalline sensing layer $(\mathrm{ZnO})$ also modulates the gas adsorption behavior and thus the sensing parameters [24]. 
Figure 9 represents the transient response for different concentrations of methane at $100^{\circ} \mathrm{C}$ using nitrogen and synthetic air as carrier gases. The response time and recovery time with increasing methane concentrations as derived from the transient response curves are shown in Table 4.

It is apparent from the table that response time is shorter than recovery time that is true also for the cases in Tables 2 and 3. The Pd-Ag/ZnO surface seems to be favorable for the adsorption kinetics at the catalytic metal and $\mathrm{Pd}-\mathrm{Ag} / \mathrm{ZnO}$ interface, compare Tables 3 and 4 , the same way the recovery time is longer than the response time for all cases in Tables $2-4$. It is interesting to note that the recovery time in Table 4 is about the same in nitrogen and oxygen, which supports the earlier discussion that the back reaction is the same in nitrogen and oxygen atmosphere due to oxygen leakage into the system.

It should be noted that the sensing of methane at $100^{\circ} \mathrm{C}$ for $\mathrm{Pd}-\mathrm{Ag} / \mathrm{ZnO}$ might be suitable for practical applications due to the high response, speed of response, and recovery, because there is no accumulation of water molecules on the sensor surface at $100^{\circ} \mathrm{C}[12]$.

We tested the long-term stability of the Schottky sensor for 33 days in presence of $1 \%$ methane in nitrogen at $100^{\circ} \mathrm{C}$, and the results are shown in Figure 10(a). It is evident from the figure that the sensors show more or less stable performance with a negligible variation of current over the above-mentioned period in a nitrogen atmosphere. We also tested the stability in synthetic air; see Figure 10(b) for 8 hours and a fairly good stability was obtained. The longterm stability in air needs to be further tested since this is the realistic atmosphere for a methane leak detector.

\section{Conclusion}

Our investigation confirms that methane can be detected at as low a temperature as $100^{\circ} \mathrm{C}$ using $\mathrm{Pd}-\mathrm{Ag}$ alloy as the Schottky contact to nanocrystalline $\mathrm{ZnO}$ thin film, obtained by anodization of $\mathrm{Zn}$ and surface modified by using noble metal, for example, $\mathrm{Pd}$. Nanocrystalline $\mathrm{ZnO}$ thin films, after Pd surface modification, showed improved sensing characteristics like large response, short response and recovery time. The stability of the sensor structure obtained in this study indicates that the sensor might be good for methane sensing in the coalmine environment.

\section{Acknowledgment}

One of the authors (P. K. Basu) gratefully acknowledges CSIR, Government of India, for a Senior Research Fellowship (SRF).

\section{References}

[1] P. K. Basu, P. Bhattacharyya, N. Saha, H. Saha, and S. Basu, "The superior performance of the electrochemically grown $\mathrm{ZnO}$ thin films as methane sensor," Sensors and Actuators B, vol. 133, no. 2, pp. 357-363, 2008.

[2] P. Bhattacharyya, P. K. Basu, H. Saha, and S. Basu, "Fast response methane sensor using nanocrystalline zinc oxide thin films derived by sol-gel method," Sensors and Actuators B, vol. 124, no. 1, pp. 62-67, 2007.

[3] P. K. Basu, P. Bhattacharyya, N. Saha, H. Saha, and S. Basu, "Methane sensing properties of platinum catalysed nano porous zinc oxide thin films derived by electrochemical anodization," Sensor Letters, vol. 6, no. 1, pp. 219-225, 2008.

[4] P. Bhattacharyya, P. K. Basu, C. Lang, H. Saha, and S. Basu, "Noble metal catalytic contacts to sol-gel nanocrystalline zinc oxide thin films for sensing methane," Sensors and Actuators B, vol. 129, no. 2, pp. 551-557, 2008.

[5] P. Bhattacharyya, P. K. Basu, H. Saha, and S. Basu, "Fast response methane sensor based on $\mathrm{Pd}(\mathrm{Ag}) / \mathrm{ZnO} / \mathrm{Zn}$ MIM structure," Sensor Letters, vol. 4, no. 4, pp. 371-376, 2006.

[6] P. K. Basu, S. K. Jana, H. Saha, and S. Basu, "Low temperature methane sensing by electrochemically grown and surface modified ZnO thin films," Sensors and Actuators B, vol. 135, no. 1, pp. 81-88, 2008.

[7] S. W. Hla, P. Lacovig, G. Comelli, A. Baraldi, M. Kiskinova, and R. Rosei, "Orientational anisotropy in oxygen dissociation on Rh(110)," Physical Review B, vol. 60, no. 11, pp. 7800-7803, 1999.

[8] A. Rothschild and Y. Komem, "The effect of grain size on the sensitivity of nanocrystalline metal-oxide gas sensors," Journal of Applied Physics, vol. 95, no. 11, pp. 6374-6380, 2004.

[9] S. L. Tait, Z. Dohnalek, C. T. Campbell, and B. D. Kay, "Methane adsorption and dissociation and oxygen adsorption and reaction with $\mathrm{CO}$ on Pd nanoparticles on $\mathrm{MgO}\left(\begin{array}{lll}1 & 0 & 0\end{array}\right)$ and on Pd(1 11 1)," Surface Science, vol. 591, no. 1-3, pp. 90-107, 2005.

[10] M.-S. Liao, C.-T. Au, and C.-F. Ng, "Methane dissociation on $\mathrm{Ni}, \mathrm{Pd}, \mathrm{Pt}$ and $\mathrm{Cu}$ metal (111) surfaces-a theoretical comparative study," Chemical Physics Letters, vol. 272, no. 56, pp. 445-452, 1997.

[11] V. R. Shinde, T. P. Gujar, and C. D. Lokhande, "Enhanced response of porous $\mathrm{ZnO}$ nanobeads towards LPG: effect of Pd sensitization," Sensors and Actuators B, vol. 123, no. 2, pp. 701706, 2007.

[12] M. Lofdahl, C. Utaiwasin, A. Carlsson, I. Lundstrom, and M. Eriksson, "Gas response dependence on gate metal morphology of field-effect devices," Sensors and Actuators B, vol. 80, no. 3, pp. 183-192, 2001.

[13] C. Xu, J. Tamaki, N. Miura, and N. Yamazoe, "Relationship between gas sensitivity and microstructure of porous $\mathrm{SnO}_{2}$," Journal of the Electrochemical Society, vol. 58, p. 1143, 1990.

[14] R. C. Hughes, W. K. Schubert, T. E. Zipperian, J. L. Rodriguez, and T. A. Plut, "Thin-film palladium and silver alloys and layers for metal-insulator-semiconductor sensors," Journal of Applied Physics, vol. 62, no. 3, pp. 1074-1083, 1987.

[15] M. Wang and Y. Feng, "Palladium-silver thin film for hydrogen sensing," Sensors and Actuators B, vol. 123, no. 1, pp. 101-106, 2007.

[16] S. Eriksson, M. Nilsson, M. Boutonnet, and S. Järås, "Partial oxidation of methane over rhodium catalysts for power generation applications," Catalysis Today, vol. 100, no. 3-4, pp. 447-451, 2005.

[17] V. A. Drozdov, P. G. Tsyrulnikov, V. V. Popovskii, N. N. Bulgakov, E. M. Moroz, and T. G. Galeev, "Comparative study of the activity of Al-Pd and Al-Pt catalysts in deep oxidation of hydrocarbons," Reaction Kinetics and Catalysis Letters, vol. 27, no. 2, pp. 425-427, 1985.

[18] R. Löber and D. Hennig, "Interaction of hydrogen with transition metal fcc(111) surfaces," Physical Review B, vol. 55, no. 7, pp. 4761-4765, 1997. 
[19] E. P. J. Mallens, J. H. B. J. Hoebink, and G. B. Marin, "The reaction mechanism of the partial oxidation of methane to synthesis gas: a transient kinetic study over rhodium and a comparison with platinum," Journal of Catalysis, vol. 167, no. 1, pp. 43-56, 1997.

[20] L. Opara, B. Klein, and H. Zuchnerh, "Hydrogen-diffusion in $\operatorname{Pd}_{1-\mathrm{x}} \operatorname{Ag}_{\mathrm{x}}(0 \leq \mathrm{x} \leq 1)$," Journal of Alloys and Compounds, vol. 253-254, pp. 378-380, 1997.

[21] I. Lundström, H. Sundgren, F. Winquist, M. Eriksson, C. Krantz-Rülcker, and A. Lloyd-Spetz, "Twenty-five years of field effect gas sensor research in Linköping," Sensors and Actuators B, vol. 121, no. 1, pp. 247-262, 2007.

[22] S. Liu, K. Takahashi, K. Fuchigami, and K. Uematsu, "Hydrogen production by oxidative methanol reforming on $\mathrm{Pd} / \mathrm{ZnO}$ : catalyst deactivation," Applied Catalysis A, vol. 299, no. 1-2, pp. 58-65, 2006.

[23] H. Zhang, R. L. Penn, R. J. Hamers, and J. F. Banfield, "Enhanced adsorption of molecules on surfaces of nanocrystalline particles," Journal of Physical Chemistry B, vol. 103, no. 22, pp. 4656-4662, 1999.

[24] V. Khranovskyy, J. Eriksson, A. Lloyd-Spetz, and R. Yakimova, "Oxygen absorption effect on the sensitivity and material stability of $\mathrm{ZnO}$ nanostructured films," in Proceedings of IEEE Sensors, pp. 874-877, Lecce, Italy, October 2008. 

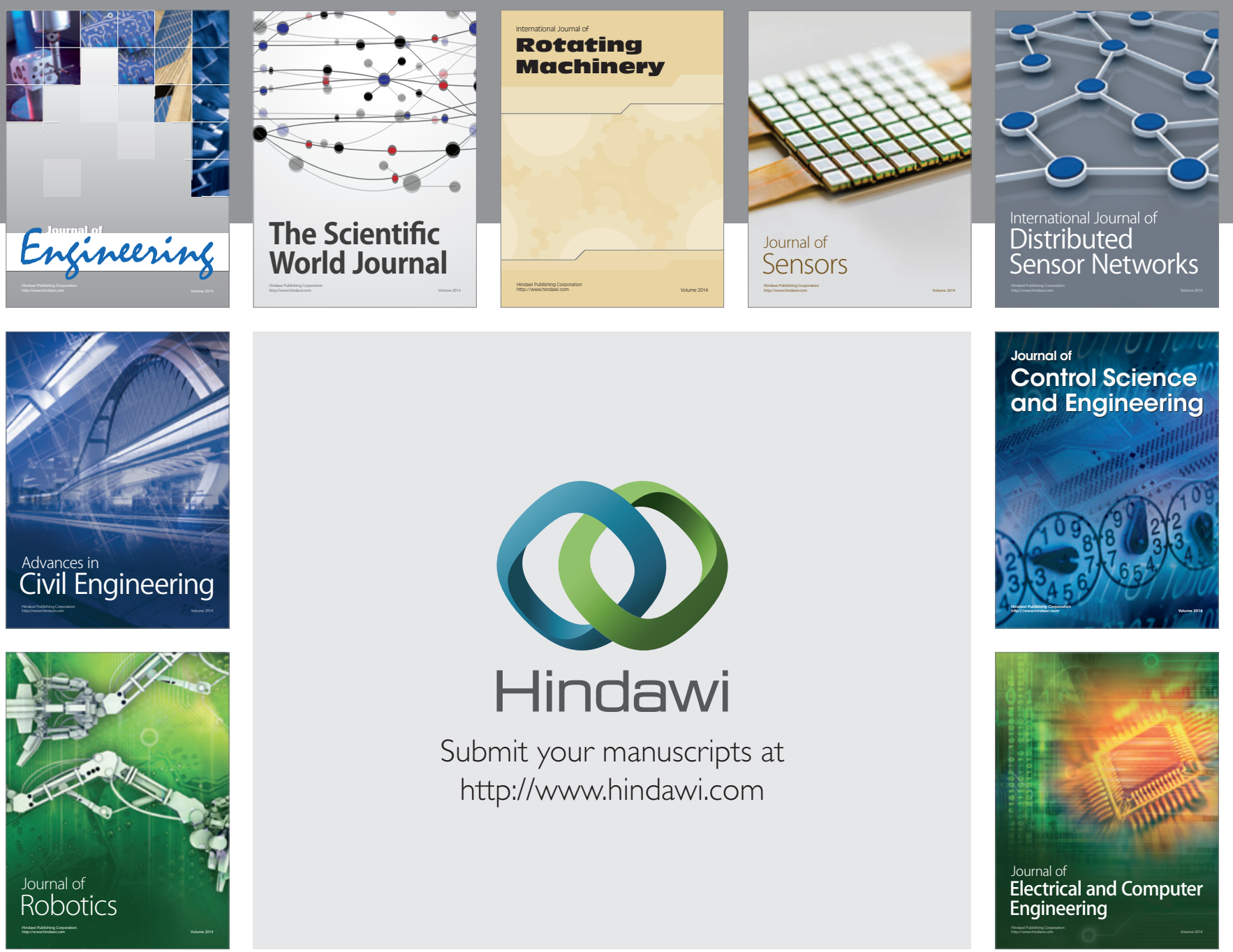

Submit your manuscripts at

http://www.hindawi.com
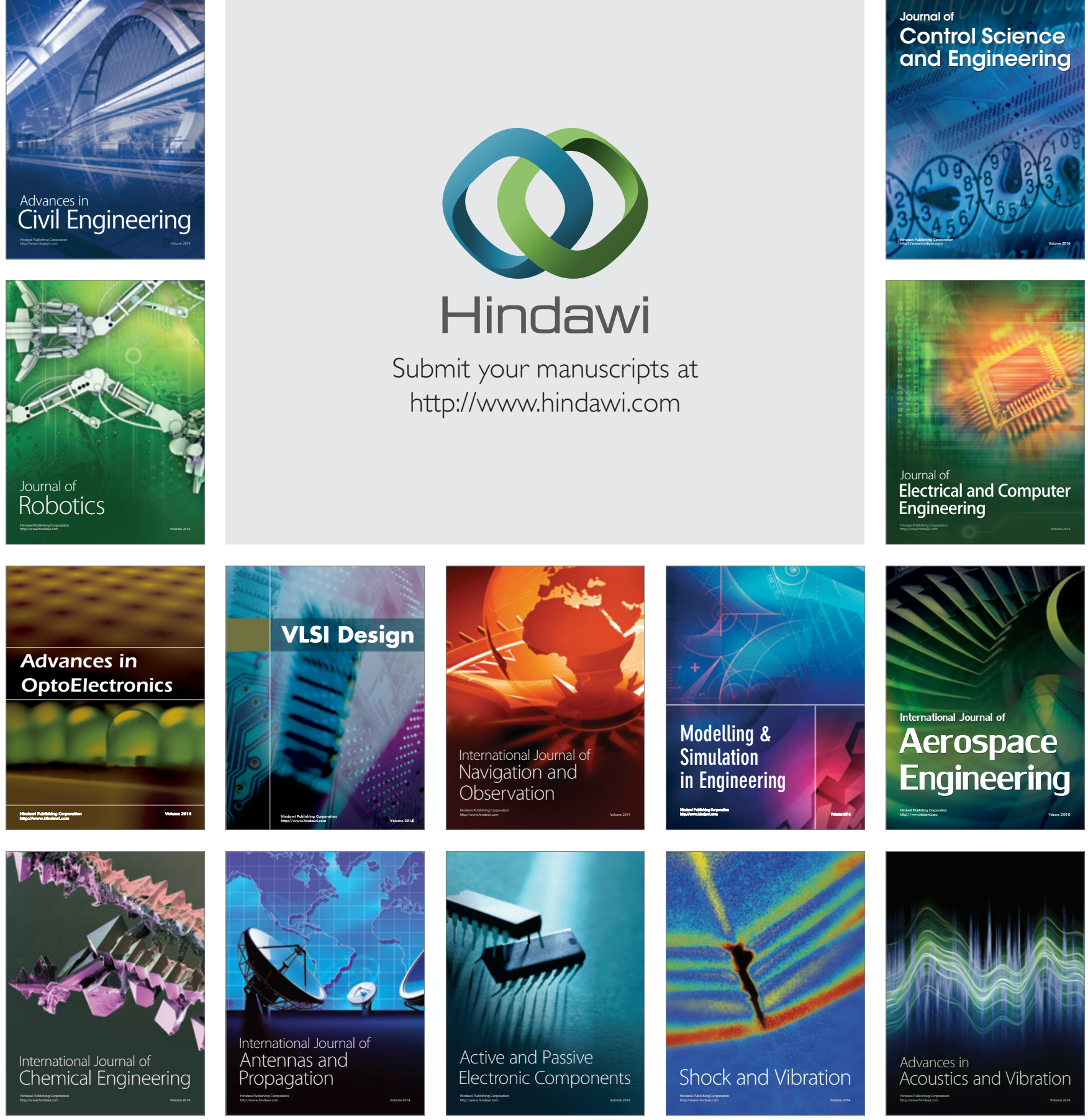